\title{
AS PRODUÇÕES SIMBÓLICAS DAS CRIANÇAS E A FORMAÇÃO DAS PROFESSORAS: INDICATIVOS A PARTIR DE UMA INVESTIGAÇÃO EM CRECHE ${ }^{1}$
}

\author{
Andréa Simões Rivero- deiarivero@gmail.com \\ Ângela Maria Scalabrin Coutinho - gi_scalabrin@hotmail.com \\ Rosa Batista-rosab@terra.com.br
}

\section{RESUMO}

Este artigo apresenta parte de um processo de pesquisa, cujo propósito é buscar indicadores para a formação de professores e para a prática pedagóg ica nos contextos de educação de educação infantil. A análise dos modos de produção simbólica das cri anças a partir da observação, registro e análise de seus modos de ser e viver é objeto deste estudo, que toma como base a interface da produção teórica e metodológica dos campos de conhecimento da Educação e da Sociologia da Infância. Articuladamente à análise dos modos de produção simbólica das crianças, buscou-se construir e promover uma formação em serviço das profissionais das instituições envolvi das na pesquisa, considerando a ampliação do conhecimento em torno dos mundos sociais, educacionais e culturais da infância e das crianças em creches e pré-escolas. A pesquisa foi desenvolvida em duas instituições de educação infantil da Rede Municipal de Educação de Florianópolis, sendo que os dados ora apresentados dizem respeito apenas a uma das instituições. $\mathrm{Na}$ referida instituição procurou-se mapear e analisar, especificamente, os repertórios de brincadeiras das crianças, tema central deste artigo. Participaram da pesquisa professoras que atuavam junto aos grupos de crianças envolvidos na investigação, além das diretoras e coordenadoras pedagógicas das duas instituições, bem como professores de diferentes universidades. A pesquisa realizada traz como indicativos a necessidade de que se rompa com o modelo de educação tradicional, e que, a partir da aproximação das professoras aos jeitos de ser das crianças, às produções simbólicas nas brincadeiras, nas diferentes linguagens e no encontro com os pares sejam construídas práticas pedagógicas que ampliem os repertórios culturais infantis. Para tanto, é preciso que as instituições de educação infantil constituam-se em espaços de formação, no sentido de se estabelecer cruzamentos férteis entre as análises das produções simbólicas infantis e elaboração de propostas pedagógicas.

Palavras-chave: Sociologia da Infância - Culturas Infantis - Brincadeira - Formação de Professores

\section{SITUANDO A EXPERIÊNCIA DE PESQUISA}

Ao longo de três anos realizamos um processo de pesquisa em duas instituições de educação infantil da Rede Municipal de Florianópo lis - Santa Catarina. Esta pesquisa ${ }^{1}$ procurou valorizar os pontos de vista de profissionais dessas instituições, a respeito do trabalho desenvolvido junto às crianças e refletir sobre suas interrogações e concepções. Tivemos a intenção de desenvolver um trabalho que auxiliasse as profissionais a se reconhecerem como sujeitos desse processo, possibilitando cruzamentos férteis entre os conhecimentos advindos da experiência vivenciada na instituição e a produção teórica da área.

\footnotetext{
${ }^{1}$ Este artigo é uma versão do trabalho apresentado no $1^{\circ}$ Congresso Internacional de Estudos da Criança "Infância possíveis, mundos reais", realizado em Braga - Portugal, 2008.
} 
Neste trabalho abordaremos especificamente o processo vivenciado em uma dessas instituições - a Creche Joaquina Maria Peres.

A partir de critérios $^{2}$ demarcados no projeto definiu -se o grupo de crianças e as respectivas professoras que participariam da pesquisa. Entretanto, essa escolha foi realizada com a equip e pedagógica da instituição e submetida aos demais profissionais que aprovaram a decisão.

O grupo que fez parte desta investigação era constituído de dezesseis crianças, com idades entre dois anos e seis meses a três anos completos. As crianças permaneciam aproximadamente dez horas diárias na creche, em período integral e residiam, na sua maioria, no bairro Itacorubi, bairro urbano residencial e de comércios de pequeno porte, localizado próximo à Universidade Federal de Santa Catarina (UFSC) e ao Centro da cidade.

O projeto de pesquisa foi apresentado e discutido com as famílias das crianças com o intuito de obter a aprovação das mesmas para a realização da investigação. Não só obtivemos sua aprovação, mas também a indicação de que os registros produzidos f ossem partilhados no decorrer da mesma, pois estes permitiriam às famílias uma aproximação às vivências das crianças na creche.

As duas professoras que atuavam, respectivamente, como professora e professora auxiliar do grupo de crianças, assumiram a função ${ }^{3}$ de observadoras internas. A formadora e a observadora externa faziam parte do Núcleo de Estudos e Pesquisas da Educação da Pequena Infância (NUPEIN) da Universidade Federal de Santa Catarina.

A opção por um observador externo e um observador interno, pa ra a realização da pesquisa, residiu na complementaridade destas duas posições, ou seja, o observador externo, em virtude de não estar presente cotidianamente junto ao grupo de crianças, tinha uma maior possibilidade de estranhar o que ali acontecia, favorecendo a formulação de perguntas sobre as ações sociais das crianças. O observador interno, em função de sua atuação regular e sistemática junto às crianças , reunia elementos diversos sobre o contexto de vida das crianças. Os dados obtidos por esses dois sujeitos, com olhares e perguntas diferenciadas a respeito das criações simbólicas das crianças, favoreceram a ampliação do conhecimento acerca das mesmas. Ao formador cabia captar as diferentes contribuições advindas dos observadores e articulá -las, buscando novos elementos para a construção da prática pedagógica a partir da análise de registros das experiências das crianças.

\subsection{A construção de um olhar sensível}

Durante o percurso de discussões e reflexões do grupo de pesquisadores, emergiu a necessidade de aprofundarmos as questões que envolviam os procedimentos metodológicos a serem 
empregados e desenvolvidos nesta investigação, a fim de capacitar todos os envolvidos, em especial, os formadores, os observadores externos e internos.

Neste sentido, foi organizada a oficina "Construindo um olhar sensível”, cujo eixo central de discussão foi a observação participante, o registro escrito, fílmico (vídeo) e fotográfico das criações simbólicas das crianças no contexto da instituição de educação infantil. Partimos do pressuposto que:

[...] mais do que olhar para observar, é preciso escutar para compreender o que elas (as crianças - grifo nosso) (nos) dizem, a partir da auscultação da sua "voz", onde a escuta das e com as crianças reclama, sobretudo, ensaiar [...] u ma nova atitude epistemológica, a da escuta sensível (BARBIER, 1993) que "supõe uma inversão da atenção. Antes de situar uma pessoa no seu lugar, começa por reconhecê -la no seu ser, na sua qualidade de pessoa complexa”. (FERREIRA, 2002, p. 153).

A construção de um olhar sensível às vivências das crianças nos espaços das instituições de educação infantil deve-se, em parte, ao contributo de outros campos de conhecimento. Da psicologia, que ao pesquisar as relações vivenciadas nesses espaços, apontou a criança enquanto foco importante de observação. Nesta perspectiva, apontou também a importância do contato entre as crianças e de se legitimar a produção de conhecimentos que é proveniente da interação entre os pares. Contudo, deve-se chamar a atenção para o fato de que a perspectiva que fundamenta tal compreensão tinha como princípio a concepção desenvolvimentista, o que impunha à abordagem uma concepção genérica de infância.

Coaduna-se a esse movimento a crescente produção na área da Sociologia da Infância e d a Antropologia em relação aos modos de ser criança e viver a infância em diferentes contextos culturais, bem como o expressivo debate em torno das culturas infantis. Contudo, no campo da antropologia ainda encontra-se resistências em relação a legitimidade das vozes infantis, pois segundo Nunes (1999, p. 37),

[...] a criança é incluída em alguns trabalhos antropológicos, porém, raramente como categoria preponderante na condução das investigações. Ela aparece nas mais diversas situações, espalhada pelos dados etnográficos dos mais atentos pesquisadores, mas dificilmente é considerada como relevante em qualquer análise que a partir destes se faça.

Metodologicamente, a contribuição desses campos é incontestável, tendo em vista que a observação participante, procedimento amplamente utilizado nas ciências sociais, tem se mostrado como o procedimento que mais nos permite conhecer as crianças, já que para isso nos parece pouco provável que não seja necessário interagir com as mesmas.

De acordo com Rocha (2004, p. 253): 
[...] estas contribuições têm indicado, para a pedagogia, a necessidade de tomar como ponto da partida da acção educativa o conhecimento sobre a criança para além daqueles definidos como padrões de desenvolvimento através da observação das crianças: o como brincam e sobre o que brincam; o cruzamento que estabelecem entre fantasia e realidade; as expressões do seu imaginário e como interpretam temas da vida cotidiana. Resulta isto em reconhecer que investigar sobre os contornos do ser criança e os processos de constituição da infância e da sua educação implica considerar a criança como agente cultural e informante qualificado.

Nosso desafio tem sido interpretar os indicativos das crianças de forma mais fidedigna possível, pois mesmo tendo claro que sempre estaremos interpretando aquilo que as crianças comunicam, ouvi-las e compreendê-las exige que tenhamos "agilidade no registro e sensibilidade no olhar" (COUTINHO, 2002).

A visualização de registros de práticas sociais das crianças possibilitou tam bém refletir sobre nossas práticas de registro, ainda muito centradas nas práticas dos adultos. Esta experiência possibilitou a construção de uma unidade de sentidos e significados acerca do papel do registro como instrumento de pesquisa (GANDINI; GOLDHABE R, 2002; DAHLBERG, MOSS; PENCE, 2003): o quê registrar, como registrar, para que registrar. Foi ficando mais claro que o foco da pesquisa eram as crianças e suas produções culturais, seus processos criativos e imaginativos.

\section{A PESQUISA NA CRECHE JOAQUIN A MARIA PERES}

O exercício de interpretação dos registros resultou na delimitação das produções simbólicas das crianças nos momentos de brincadeira, como foco de pesquisa na creche Joaquina Maria Peres e, na definição das primeiras questões orientadoras da s observações: Que elementos culturais estão presentes nas brincadeiras? Que brincadeiras as crianças criam? Que relações as crianças estabelecem durante a brincadeira? Que suportes materiais e imateriais promovem as produções simbólicas das crianças?

Atuar como observadores das práticas das crianças, partilhando impressões sobre a realidade captada foi um exercício vivido ao longo da pesquisa, que permitiu algumas reflexões sobre suas brincadeiras. Esse processo desencadeou uma maior sensibilização em rela ção às manifestações e criações das crianças durante as brincadeiras, em decorrência disto as observações, reflexões e análises dos registros ocorreram com maior regularidade e aprofundamento.

As profissionais envolvidas na pesquisa iam se compreendendo c omo sujeitos de seu processo de formação à medida que assumiam o papel de observadoras e investigadoras das 
produções simbólicas das crianças no contexto da creche. Ao atuarem como observadoras das práticas das crianças partilhavam suas impressões sobre a realidade captada, descobrindo diferentes olhares sobre uma mesma situação, formulando diferentes proposições para ampliar os repertórios culturais das crianças de forma individual e coletiva.

Ao registrar essa experiência uma das professoras ${ }^{4}$ da creche, envolvida na pesquisa, relata que:

À medida em que o grupo foi construindo vínculos de confiança, estes encontros começaram a ser muito verdadeiros, e os professores aprenderam a comentar suas práticas, apontando os seus limites. A cada reencontro, novos desafios, desafios em relação ao trabalho com as crianças e também quanto à necessidade que os professores sentiam na construção de seus conhecimentos. (MEKSENAS, 2003, p. 1)

A reflexão e a análise dos registros realizados pelas professoras (observadoras internas) foram o foco central dos encontros subseqüentes. A riqueza dos registros realizados por elas a respeito das brincadeiras do grupo de crianças provocou muitas interrogações, não apenas sobre as brincadeiras em si, mas também sobre a organização d o tempo e do espaço, sobre a lógica de organização dos brinquedos e materiais, sobre o papel do/a professor/a no contexto das brincadeiras, sobre o planejamento e a ampliação dos repertórios de brincadeiras das crianças. Tal fato determinou a necessidade de um aprofundamento das discussões sobre os materiais produzidos pelas professoras e as possibilidades de planejamento de um cotidiano que favorecesse a imaginação, a fantasia, o faz-de-conta. Isto é evidenciado na reflexão feita pela mesma professora:

[...] encontramos dificuldades em relação à organização dos registros, notamos que muito do que falamos sobre as ocorrências com o grupo de crianças se perde no momento do planejamento e por falta de uma sistematização das atividades desenvolvidas. Por outro lado é a possibilidade de pensar e falar sobre estes limites do trabalho que nos permite repensar $o$ ato de planejar e também o desenvolvimento do mesmo. (MEKSENAS, 2004, p. 1).

Promover práticas de planejamento do trabalho pedagógico a partir da observaçã o, registro e reflexão das brincadeiras das crianças era um dos objetivos gerais desta pesquisa que, ao longo do processo de reflexão sistemática acerca dos registros, foi se tornando cada vez mais uma necessidade das professoras como indica uma das observ adoras internas, a professora auxiliar ${ }^{5}$ do grupo:

Planejar o trabalho para as crianças e com elas, é sem dúvida, fundamental e indiscutível. Pensamos então, na organização do espaço e de novos materiais de maneira que estes pudessem desencadear novas poss ibilidades de elaboração para as experiências das crianças e suas significações nas brincadeiras. (CRUZ, 2004, p. 1) 
Foi ficando cada vez mais evidente a necessidade de conhecer os repertórios das brincadeiras das crianças com intuito de valorizar suas c riações simbólicas e ampliá-las. Todavia, para analisar e interpretar tais repertórios, foi preciso estudar a temática da brincadeira, a partir de algumas produções teóricas ${ }^{6}$ e isso foi feito simultaneamente ao processo de elaboração de registros.

\subsection{As produções simbólicas das crianças na Creche Joaquina Maria Peres}

Durante o processo de produção de registros, tornou -se evidente a necessidade de mapear os repertórios das brincadeiras realizadas pelas crianças desse grupo. As professoras destacaram algumas brincadeiras que, a seu ver, ocorriam com maior regularidade: a brincadeira de casinha; de mamãe e filhinha; de caminhão de lixo; de bombeiro; de supermercado Rosa ${ }^{7}$; de Lobo Mau; de pista de carro e de pescar.

Ao discorrer sobre essas brincadeiras, percebeu-se que não bastava saber do que aquelas crianças brincavam de modo genérico, era necessário conhecer como elas construíam suas brincadeiras e os possíveis significados contidos nas mesmas.

Não era suficiente, portanto, afirmar que as crianças brincav am de "casinha", de "lobo", de "mamãe e filhinha", pois isso não traduzia o que ocorria durante essa brincadeira. Tratava -se de procurar conhecer as significações produzidas por aquelas crianças naquele contexto social, isso exigia rever os modos como tradicionalmente aprendeu-se a olhar para as ações sociais das crianças, entre elas as brincadeiras.

Discutiu-se que a construção de um outro olhar em direção às crianças se dá na relação com elas, na medida em que nos propomos a olhar atentamente e a ouvir o que têm a dizer. Nessa perspectiva, buscou-se construir junto às professoras práticas de observação e registro que permitissem captar detalhadamente as ações das crianças no desenvolvimento das suas brincadeiras. Esse processo foi desencadeando um moviment o de aproximação e estranhamento em relação aos modos como as crianças brincavam. Contudo, registrar com essa intenção diferenciava -se do modo como costumava-se registrar o cotidiano. Assim, a aprendizagem desse outro modo de documentar as ações das crianças deu-se no próprio exercício de registrar os movimentos, os gestos, as falas, os usos que as crianças faziam dos objetos, dos tempos e espaços.

A descrição detalhada das situações vividas pelas crianças possibilitou uma outra relação com os universos de brincadeira, que até então pareciam conhecidos e naturais. Entretanto, a reflexão coletiva sobre estes registros foi evidenciando o "não saber" dos adultos a respeito das 
produções simbólicas daquele grupo. O reconhecimento deste "não saber" possibilitou também repensar que o foco de nossas reflexões

[...] tem sido centrado muito mais na prática dos adultos do que nas práticas das crianças. Não estamos dizendo que um deva se sobrepor ao outro, mas sim que devemos incluir em nossas reflexões sobre educação infantil um aspecto fundamental - os direitos das crianças de serem consultadas e ouvidas, de exercerem sua liberdade de expressão e opinião e o direito de tomarem decisões em seu proveito. (BATISTA et al, 2004, p. 3)

O movimento de interrogar-se sobre os modos como as crianças viviam as brincadeiras contribuiu para romper com uma atitude do adulto como aquele que apenas constata a brincadeira e que a concebe somente como um processo de imitação da realidade. Nesta perspectiva, Corsaro (2002, p. 114) afirma que:

[...] a produção de cultura de pares não se fica nem por uma questão de simples imitação nem por uma apropriação directa do mundo adulto. As crianças apropriam-se criativamente da informação do mundo adulto para produzir a sua própria cultura de pares. Tal apropriação é criativa na medida em que tanto expande a cultura de pares (transforma a informação do mundo adulto de acordo com as preocupações do mundo de pares) como simultaneamente contribui para a reprodução da cultura adulta.

À medida que os adultos aproximam-se das criações simbólicas das crianças, simultaneamente têm a possibilidade de rever e ampliar seus conhecimentos acerca de seus universos de vida.

[...] o estudo das crianças a partir de si mesmas permite des cortinar uma outra realidade social, que é aquela que emerge das interpretações infantis dos respectivos mundos de vida. $\mathrm{O}$ olhar das crianças permite revelar fenómenos sociais que o olhar dos adultos deixa na penumbra ou obscurece totalmente. Assim, interpretar as representações sociais das crianças pode ser não apenas um meio de acesso à infância como categoria social, mas as próprias estruturas e dinâmicas sociais que são desocultadas no discurso das crianças. (SARMENTO; PINTO, 1997, p. 25).

A compreensão da importância da brincadeira - a partir da observação das experiências das crianças - como espaço de reprodução-produção cultural conduziu, portanto, à decisão de planejar os espaços, os suportes materiais com a intenção de ampliar o conhecimento acerca das produções simbólicas, como também a ampliação dos repertórios culturais das crianças.

Uma das professoras reflete sobre o processo de planejamento a partir das análises dos registros das brincadeiras das crianças:

Pensando sobre a forma de planejar a partir de indicativos das crianças e também dos diversos olhares, iniciamos algumas ações em relação ao espaço físico e à ampliação de conteúdos oferecidos às crianças. 
Construímos módulos de madeira e as crianças pintaram para servir de divisórias, ao mesmo tempo, tais módulos serviram para guardar objetos e/ou como suporte de algumas brincadeiras. Combinamos que a partir das brincadeiras de lobo mau, ampliaríamos o repertório de histórias. Conversamos sobre a importância de contar, ler, dramatizar histórias no cotidiano [...]. A partir das observações já existentes em relação às proposições das crianças, os adultos organiza ram materiais como toquinhos de madeira, materiais de sucata, Cds musicais diversos e um acervo maior de histórias infantis. Esta organ ização dos materiais permitiu novos enredos de brincadeiras - de fadas, bruxas, navio, pescaria, carros de transp orte - e a produção de novos instrumentos musicais. (MEKSENAS, 2004, p. 2) .

Então, a partir da análise e interpretação de registros de brincadeiras das crianças, as professoras propuseram-se a ampliar os repertórios das crianças, como relatam no registro a seguir:

O movimento de registro e reflexão de nossas ações e das ações das crianças nos remeteu a considerar situações que vinham ocorrend o no grupo de crianças em relação à fantasia e a imaginação. A partir das brincadeiras de Lobo Mau, decidimos apresentar outros elementos buscando diversificar, os repertórios das crianças como: histórias de bruxas, fadas, duendes, rei, rainha, castelos. (Registro escrito realizado pelas professoras Ana Alice Dias e Maria H. da Cruz em 09/12/2004)

A análise dos registros das ações das crianças foi dando visibilidade para os seus modos próprios de representação do mundo, suas criações, sua estética, suas pr oduções culturais. De acordo com Sarmento (2004, p. 21):

[...] as culturas da infância possuem, antes de mais, dimensões relacionais, constituem-se nas interacções de pares entre crianças e adultos, estruturando -se nessas relações formas e conteúdos repres entacionais distintos. As culturas da infância exprimem a cultura societal em que se inserem, mas fazem -no de modo distinto das culturas adultas, ao mesmo tempo que veiculam formas especificamente infantis de inteligibilidade, representação e simbolização do mundo.

Uma das situações registradas provoca a pensar sobre as formas representacionais próprias das crianças, seus modos de ser e estar na relação com seus pares e com os adultos:

Perguntei às crianças: _O que mais poderíamos fazer para enfeitar a sala?

A Rebeca disse: - A Bruxa. E começou a rasgar papéis, amassá-los e colá-los com fita adesiva. Em seguida Rebeca pede ajuda para uma das professoras: - Me ajuda Maria ... a fazer a cabeça, eu quero bem grande.

Rebeca colou as pernas na cabeça da Bruxa com muita fita e depois fixou a mesma na porta da sala. Na mesma mesa estavam Júlia, Anna Paula e Paola iniciando algo.

Questionei sobre o que estavam fazendo e elas responderam: - A Bruxa.

Júlia amassou e recortou folhas de revista e fez a cabeça. Olh ou para a boca da Bruxa e disse: _ó a boca deu risadinha. Pegou o papel celofane verde e colou na cabeça, estava pronto o cabelo.

Júlia, Anna Paula e Paola falaram: - Bruxa malvada.

Anna Paula fez os braços e as pernas e com a ajuda da Paola colou -as à cabeça. 
Júlia disse: - O braço na cara. E em seguida dá uma risadinha.

Falei para as meninas onde deveriam colocar os braços e as pernas.

Júlia disse: - A Bruxa é minha, da Paola e da Anna Paula.

Depois Rebeca disse: - Eu quero escrever o nome, me dá a tua caneta. Ela desenhou a Bruxa e algumas letras, pegou a fita adesiva e colou a folha ao lado da Bruxa.

(Registro da professora Ana Alice Dias, 29/10/2004)

A situação descrita explicita um movimento das professoras em acolher as idéias das crianças, possibilitando a concretização das suas intenções, seus desejos, numa relação de pares, na qual o ponto de vista do outro, a interação, permite que as crianças ressignifiquem e produzam suas culturas.

Melhor se compreendem assim as crianças como produtoras activas dos seus mundos de crianças, ou seja, como capazes de elaborar uma ordem social infantil que é uma visão intersubjectiva do mundo e o modo de estar no mundo, construído social e culturalmente nas interações, relações sociais e dinâmicas de socialibilidade próprias no contexto do JI. É aí que decorrentes da adopção, do confronto e contraponto à ordem adulta e/ou entre os pares, emergem rotinas, regras e princípios de acção no interior do grupo de crianças, os quais, apropriados na interacção social, são por elas usados como conhecimentos e competências sociais para participarem no mundo adulto e, ao mesmo tempo, para se afirmarem perante ele. (FERREIRA, 2004, p. 61).

As proposições das professoras constituem-se em suportes estruturantes das novas experiências e da construção de conhecimentos pelas crianças. Os artefatos culturais que são disponibilizados a elas permitem que correlacionem o que já sabem e pensam com aquilo que estão tendo a oportunidade de conhecer.

Pensar que a base da criação é a realidade provoca a necessidade de oferecer espaços e tempos diversificados, que propiciem a ampliação dos mundos culturais das crianças. Essas experiências permitem que os adultos se aproximem dos processos de significação realizados pelas crianças. Na fala de uma das professoras "[...] legitimar as ações das crianças - amplia os nossos próprios repertórios culturais” (MEKSENAS, 2004, p. 2).

\section{INDICAÇÕES PARA UMA PEDAGOGIA DA INFÂNCIA}

O processo de pesquisa vivido reafirma a constituição de uma Pedagog ia da Infância constítuida por relações educativas apoiadas na manifestação cultural, na criação, nas expressões, na troca e na comunicação entre os pares.

Este modo de conceber a prática pedagógica para as crianças pequenas, emerge, sobretudo, da contribuição de estudos de áreas como a sociologia da infância, a antropologia e a educação, em 
que as crianças e os adultos são vistos como partícipes, como atores sociais ativos nos processos educativos.

Este olhar para a educação da infância exige que se rompa com o modelo de educação tradicional e que a partir da aproximação das professoras aos jeitos de ser das crianças sejam construídas práticas pedagógicas que ampliem os repertórios culturais infantis a partir das suas produções simbólicas nas brincadeiras, nas diferentes linguagens e no encontro com os pares. Para tanto, é preciso que as instituições de educação infantil constituam -se em espaços de formação, no sentido de se estabelecer momentos de análise das produções simbólicas infantis e elaboração de propostas pedagógicas.

\section{REFERÊNCIAS}

BATISTA, Rosa; CERISARA, Ana Beatriz; OLIVEIRA, Alessandra MARA Rotta de; RIVERO, Andréa Simões (2004). Partilhando olhares sobre as crianças pequenas: reflexões sobre o estágio na educação infantil. In: $12^{\circ}$ Encontro Nacional de Prática de Ensino (ENDIPE), Curitiba. Conhecimento Local e Conhecimento Universal. CD Room.

BECCHI, Egle; BONDIOLI, Anna (2003). Avaliando a Pré-escola: uma trajetória de formação de professoras. Campinas, SP: Autores Associados.

BROUGÈRE, Gilles (1998). A criança e a cultura lúdica. In: KISHIMOTO, Tizuko Morchida. O brincar e suas teorias. São Paulo: Pioneira, p. 19 - 32.

CERISARA, Ana Beatriz (1998). De como Papai do Céu, o Coelhinho da Páscoa, os anjos e Papai Noel foram viver juntos no céu. In: KISHIMOTO, Tizuko Morchida. O brincar e suas teorias. São Paulo: Pioneira, p. $123-138$.

CORSARO, Willian A (2002). A reprodução interpretativa do brincar ao "faz-de-conta" das crianças. In: Educação, Sociedade e Culturas, nº 17, p. 113 - 134.

COUTINHO, Angela Maria Scalabrin (2002). Criações e manifestações das culturas infantis. In: _. As crianças no interior da creche: a educação e o cuidado nos momentos de sono, higiene e alimentação. Florianópolis, SC. Dissertação de Mestrado. Universidade Federal de Santa Catarina, p. 103 -137.

CRUZ, Maria Hllesheim (2004). Os materiais como suporte para as brincadeiras. Florianópolis (texto não publicado).

FERREIRA, Manuela (2003). Os estranhos <<sabores〉> da perplexidade numa etnografia com crianças em Jardim de Infância. In: CARIA, Telmo H. (org.). Experiência etnográfica em Ciências Sociais. Porto: Edições Afrontamento, p. 149-166.

(2004) Do "avesso" do brincar ou... as relações entre pares, as rotinas da cultura infantil e a construção da(s) ordem(ens) social(ais) instituinte(s) das crianças no Jardim-de-Infância. In: Sarmento, Manuel J.; CERISARA, Ana Beatriz (orgs). Crianças e Miúdos: perspectivas sociopedagógicas da infância e educação. Porto, Portugal: Edições ASA, p. 55 - 104.

GANDINI, Lella; GOLDHABER, Jeanne (2002). Duas reflexões sobre a documentação. In: GANDINI L.; EDWARDS C. (orgs). Bambini: a abordagem italiana à educação infantil. Porto Alegre: ArtMed, p. 150-169

MEKSENAS, Mariza Aparecida (2003). Creche Joaquina Maria Peres: síntese do processo de formação. Florianópolis (texto não publicado). 
MOSS, P., DAHLBERG; PENCE, A (2003). Documentação Pedagógica: Uma prática para a reflexão e para a democracia. In: MOSS, P.; DAHLBERG, G; PENCE, A. Qualidade na educação da primeira infância: perspectivas pós-modernas. Tradução de Magda F. Lopes. Porto Alegre: ArtMed, p. 189 - 208.

NUNES, Ângela (1999). A sociedade das crianças A'uwe -xavante: por uma antropologia da criança. (Temas de Investigação, $\left.n^{\circ} 8\right)$. Lisboa: Instituto de Inovação Educacion al/ Ministério da Educação.

ROCHA, Eloísa Acires Candal (2004). Crianças e Educação: caminhos da pesquisa. In: Sarmento, Manuel J.; CERISARA, Ana Beatriz (orgs). Crianças e Miúdos: perspectivas sociopedagógicas da infância e educação. Porto, Portugal: Edições ASA, p. 245 - 256.

SARMENTO, Manuel Jacinto (2004). As culturas da infância nas encruzilhadas da segunda modernidade. In: Sarmento, Manuel J.; CERISARA, Ana Beatriz (orgs). Crianças e Miúdos: perspectivas sociopedagógicas da infância e educação. Port o, Portugal: Edições ASA, p. 9 - 34.

\footnotetext{
${ }^{1}$ Esta pesquisa denominada "Culturas da infância: as produções simbólicas das crianças e das professoras de educação infantil - CIPROCEI" é um sub-projeto do projeto As Marcas dos Tempos (MATO), que teve como foco as produções simbólicas materiais (desenhos, esculturas, textos verbais, outros artefatos) feitas por crianças de diferentes proveniências étnicas e culturais, a partir das respectivas marcas históricas e identitárias (o artesanato português, as pinturas corporais índias, os ritmos e lendas afro -americanas, etc.) com promoção de trocas culturais e "re -escrita" das marcas culturais alheias, numa perspectiva de interculturalidade ativa.

${ }^{2}$ Adotou-se os seguintes critérios para a seleção das professoras: profissionais efetivas, com 40 horas semanais de trabalho na instituição, que permanecessem com o mesmo grupo de crianças durante a realização da pesquisa e que demonstrassem interesse em participar da mesma.

${ }^{3}$ A definição destas funções foi inspirada na experiência italiana relatada no livro "Avaliando a Pré-escola: uma trajetória de formação de professoras" organizado por Egle Becchi e Anna Bondioli (2003).

Observador interno: pesquisadores que atuam como professor(a) e auxiliar de sala dos grupos observados. Sua função é a de observar e registrar quotidianamente situações da rotina, que servem como material para conhecermos as produções simbólicas das crianças. Observador externo: pesquisador externo às instituições investigadas que também tem a função de observar e registrar situações da rotina junto ao grupo de crianças investigado. A meta é a construção de um diálogo constante (semanal) entre observadores internos e externos e formadores tendo por base os registros realizados. Formador: Pesquisador externo às instituições investigadas, que já desenv olve um trabalho de formação em serviço nas mesmas. Tem como função mediar a discussão entre os observadores - internos e externos - e os demais profissionais que atuam nas instituições. Coordenador Pesquisador externo às instituições investigadas que trabalha em parceria com os formadores e os observadores externos, responsável pela coordenação de todos os envolvidos. Equipe de apoio: Pesquisadores envolvidos na pesquisa com o objetivo de contribuir com as análises e reflexões realizadas pelo grupo e que não participaram diretamente das atividades desenvolvidas nas instituições investigadas.

${ }^{4}$ Mariza Aparecida Meksenas, que atuava como uma das observadoras internas, foi a relatora dos encontros ocorridos na instituição e narra esta experiência no texto Creche Joaquina Maria Peres: sintese do processo de formação (2003).

${ }^{5}$ Maria Hillesheim Cruz, que atuava como uma das observadoras internas produziu o texto "Os materiais como suporte para as brincadeiras" (2004).

${ }^{6}$ Algumas das produções teóricas estudadas com as profissionais da instituição foram: Brougère (1995,1998), Cerisara (1998) e Corsaro (2002).

${ }^{7}$ O Supermercado Rosa é um estabelecimento comercial localizado próximo à Creche.
} 